\title{
Implementation of ABMS with Cuk Converter for Enhanced Battery Life using Internet of Things
}

\author{
Juhi Jasiha E | Dr Rajeswari R
}

Depatrment of Electrical and Electronics Engineering, Government College of Technology, Coimbatore, India.

\section{To Cite this Article}

Juhi Jasiha E \& Dr Rajeswari R. Implementation of ABMS with Cuk Converter for Enhanced Battery Life using Internet of Things. International Journal for Modern Trends in Science and Technology 7, 107-111 (2021).

\section{Article Info}

Received on 15-April-2021, Revised on 02-May-2021, Accepted on 08-May-2021, Published on 14-May-2021.

\section{ABSTRACT}

This paper describes about implementing absolute battery monitoring system using IoT (Internet of things) for enhanced battery life of BFEV. Cuk converter is used to give ripple less voltage to the battery and also the converter operates in both normal and regenerating modes. The converter is designed as $\mathrm{Vs}=20 \mathrm{~V}, f \mathrm{~s}=50 \mathrm{kHz}$ with $80 \%$ of duty cycle for a $12 \mathrm{~V}$ battery. For enhanced battery life, proper battery monitoring is important to analyze the battery performance. For SOC determination of battery, voltage method is used to identify the battery status by Proteus simulation software. The main aim is to analyze the sensitivity of the electrochemical model parameters under a real-world driving cycle for not only the terminal voltage, but also the essential states in an ABMS including the smart alerting and notification system through SMS using SIMCOM GSM modem in order to intimate the user regarding the battery level status.

KEYWORDS: Cuk converter; BFEV; IoT;SOC;ABMS; SIMCOM; GSM.

\section{INTRODUCTION}

Petroleum resources across the world is depleting at a high rate due to the large dependency of the transportation sector on petroleum as the primary fuel. Also, due to this there is a vast greenhouse gas emission that is degrading the quality of air and causing harm to life and environment. Therefore an alternate propulsion technologies have been increasingly pursued by the automobile industries and this led to the increased development rate of the Hybrid Electric Vehicles (HEV) or Battery Fed Electric Vehicle technology (BFEV) for the past two decades.

One of the main considerations for the BFEV drives is to improve the efficiency of the motor drive. This can be done by a bidirectional DC-DC converter as it increases the voltage level and reduce the high currents and thus limits theassociated losses. These features of bidirectional DC-DC converter makes it as a better option for power conversion in the BFEV and thereby reducing overall cost, size and weight of the system along with increasing efficiency and achieve regenerating energy. This paper describes about an idea of using Cuk converter for the performance of two wheeled vehicles.

DC motors are generally used for many applications like electric railway traction and many more industrial fields such as rolling mills, paper industries etc, as they provide a high starting torque. The advantage of DC motor over AC motors that the range of speed control. In DC motor we can control the speed below and above the rated speed by using different methods and techniques. The speed control above the rated speed is achieved by using field current control method and below the rated speed by varying the armature voltage known as armature voltage control method. zero to rated speed.While in the field control, the speed control range from constant reference speed up to 
$120 \%-130 \%$ rated speed can be achieved but with loss of the motor developed torque.

\section{STRUCTURE OF PAPER}

The paper is organized as follows: In Section 1 , the introduction of the paper is provided along with the structure, important terms, objectives and overall description. In Section 2 we discuss related work. In Section 3 we discuss about the cuk converter and its operation. Section 4 discuss about ABMS for enhanced battery life and method of SOC determination of battery used. Section 5discuss about the simulation and results obtained during battery monitoirng. Section 6 tells us about the future scope and concludes the paper with references.

\section{OBJECTIVES}

This project aims toto analyze the sensitivity of the electrochemical model parameters under a real-world driving cycle for not only the terminal voltage, but also the essential states in an ABMS including the smart alerting and notification system through SMS using SIMCOM GSM modem in order to intimate the user regarding the battery level status.

\section{RELATED WORK}

Rouzbeh Reza Ahrabi, Hossein Ardi, Mahdi Elmi, And Ali Ajami[1] proposed a multi-input DC-DC converter and studied for hybrid electric vehicles (HEVs). Compared to conventional works, the output gain is enhanced. Fuel(FC), photovoltaic (PV) panel and energy storage system(ESS) are the input sources for proposed converter. The FC is considered as the main power supply and roof-top $\mathrm{PV}$ is employed to charge the battery, increase the efficiency and reduce fuel economy. The converter has the capability of providing the demanded power by load in absence of one or two resources. Moreover, power management strategy is described and applied in control method. A prototype of the converter is implemented and tested to verify the analysis.

G.Shruthi, Mr.SrinivasSingirikonda[2]proposed a PFC CUK converter-fed BLDC motor drive with improved power quality at the ac mains. The speed control of BLDC motor and PFC at ac mains has been achieved using a single voltage sensor. The switching losses in the VSI have been reduced by the use of fundamental frequency switching by electronically commutating the BLDC motor. Moreover, the speed of the BLDC motor has been controlled by controlling the dc link voltage of the
VSI. Therefore, the BLDC motor is electronically commutated such that the VSI operates in fundamental frequency switching for reduced switching losses and the bridgeless configuration of the Cuk converter offers low conduction losses due topartial elimination of diodebridge rectifier at the front end.

A.N. Ravishankar, S. Kumaravel And S. Ashok[3]analysed a non-isolated bidirectional dual input single output (BDISO) dc-dc converter for electric vehicle charger application. The BDISO converter is designed for utilizing solar PV along with the utility grid to charge the battery of the electric vehicle with the bidirectional power flow capacity. The operation of the converter with analytical waveforms, hardware prototype, experimental results, loss breakdown analysis and efficiency analysis, etc., are discussed in the paper. Compared to the conventional converter recently reported in the literature, the BDISO dc-dc converter uses three semiconductor switches, one inductor and one capacitor. Experimentally, the maximum efficiency of $90 \%$ is achieved in the proposed converter.

Gergana Vacheva, Nikolay Hinov And Vladimir Dimitrov[4]analysed about modelling, design consideration and control of a bidirectional DC/DC buck-boost converter for application in hybrid and electric vehicles. The proposed model includes electric motor, dynamics of the vehicle and theirs control. A mathematical model of the DC/DC buck-boost converter is described with differential equations during the both the boost and buck regions of operation. The control system is created and realized with proportional-integral regulator. The proposed solution is realized in visual environment MATLAB/Simulink. The obtained results demonstrates that the proposed solution is suitable for different electric vehicles applications.

\section{CUK CONVERTER}

The Cuk converter allows energy to flow bidirectionally by using a diode and a switch. The general circuit diagram of a Cuk converter is shown in Figure 1.

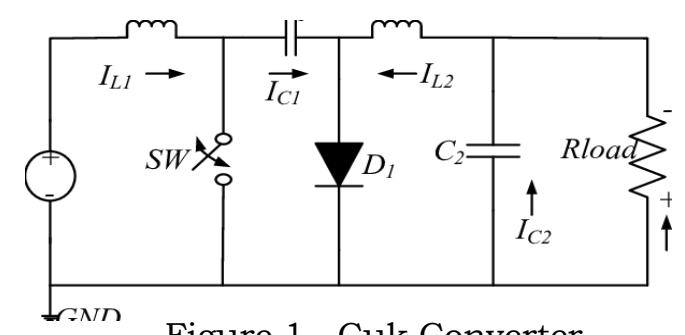

Figure 1 Cuk Converter 


\section{Modes Of Operation}

The Cuk converter modes of operation are as follows,
A. CCM Operation
B. DICM (Li) Operation
C. DICM (Lo) Operation
D. DCVM (C1) Operation

1-The load is supplied by PV and FC and battery is not used.

2-The load is supplied by PV, FC and battery, in this state battery is in discharging mode.

3-The load is supplied by PV and FC and battery is in charging mode shown below in Figure 2.

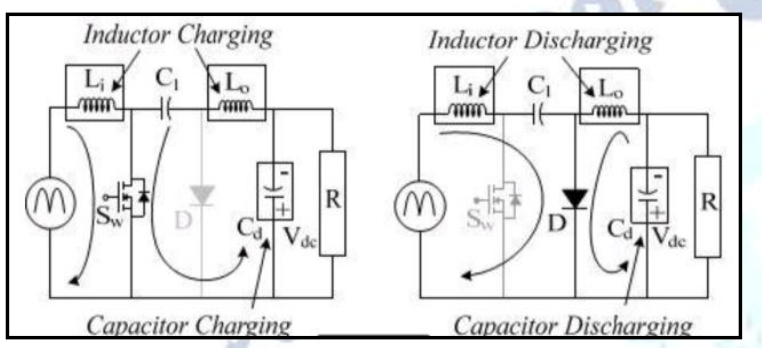

Figure 2 cuk charging and discharging

The converter is modeled for threedifferent operational states and utilized todesign a propercontroller.

\section{ABMS FOR ENHANCED BATTERY LIFE}

In this paper, state of charge (SOC) estimation for a battery is proposed and observed for monitoring. Many types of methods are developed for a battery pack, designed specifically for light electric vehicle (electric scooter or bicycles) applications. The block diagram of the proposed work for ABMS tracking of battery status is given below in Figure 3 .

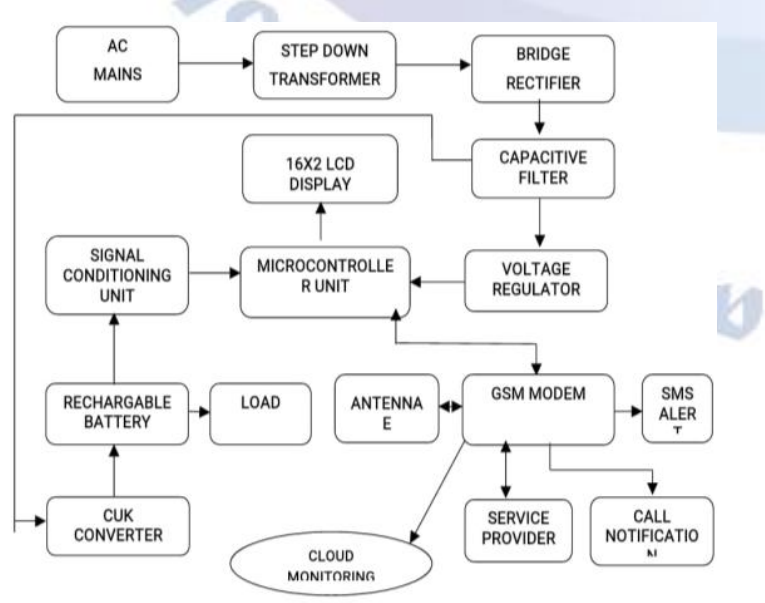

Figure 3 Block diagram of ABMS for battery life

\section{SOC Determination Of Battery}

SOC determination of a battery is to know the energy available in the battery and to find the lifetime of the battery.There are many methods to determine the SOC of the battery and most of them depends upon electrochemical characteristics and real-time working conditions of the battery. Battery current, cell voltage and cell temperature are the main parameters for estimation of battery SOC. This paper uses voltage method of SoC estimation to analyse the battery performance.

\section{SIMULATION AND RESULTS}

Proteus simulating software is used to identify the battery level of charging and battery status using Internet Of Things (IOT). For enhanced battery life, proper battery monitoring is important analyze the battery performance. The simulation model of the battery monitoring is shown in Figure 4.

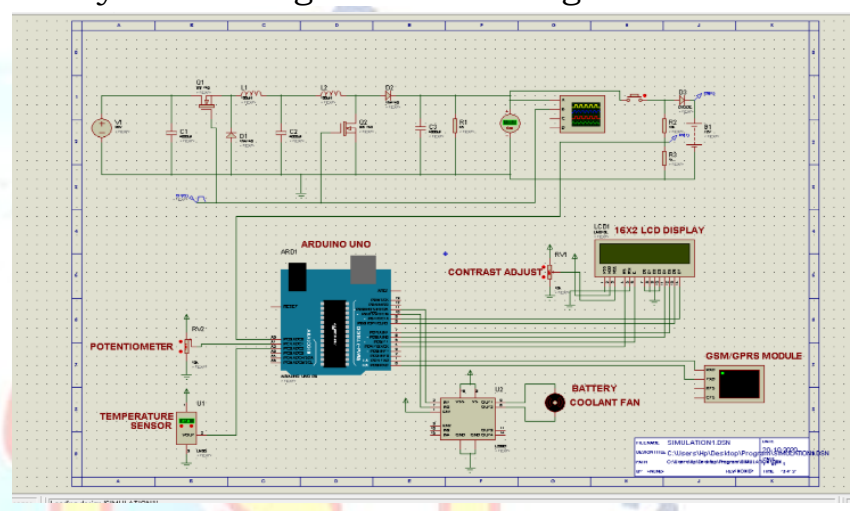

Figure 4 Simulation Model

\section{Battery monitoring based on voltage method}

For SOC determination of battery, voltage method is used to analyze the performance of the battery. The design parameters for the converter is given,

Input voltage $=20 \mathrm{~V}$

Inductors $=180 \mu \mathrm{H}(\mathrm{L} 1, \mathrm{~L} 2)$

Capacitors $=4000 \mu \mathrm{F}(\mathrm{C} 1, \mathrm{C} 2, \mathrm{C} 3)$

Resistors $=40 \mathrm{ohm}$ (R1), 10kohm (R2), $1 \mathrm{kohm}(\mathrm{R} 3)$

Switching frequency $=50 \mathrm{kHz}$

The less ripple output voltage from the converter is given below in Figure 5 .

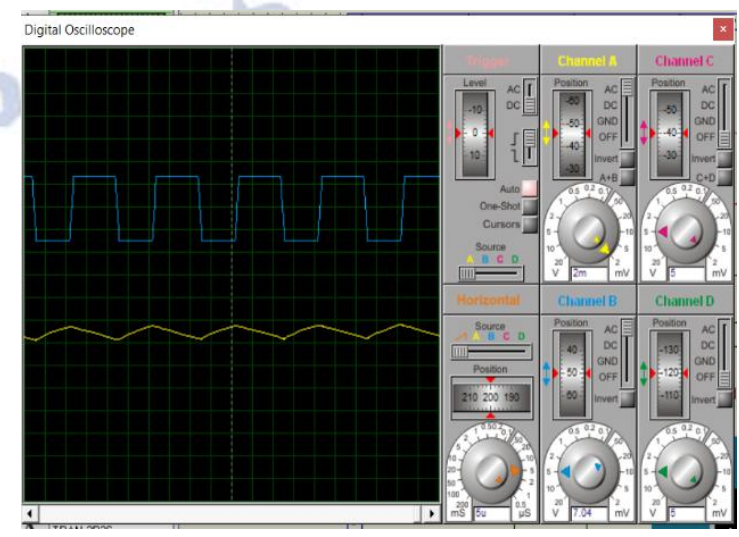

Figure 5 Output voltage of Cuk converter 
The various stages of battery monitoring are identified in the following steps. The first step of simulation is the initial level of battery status during battery monitoring is shown in figure 6 .

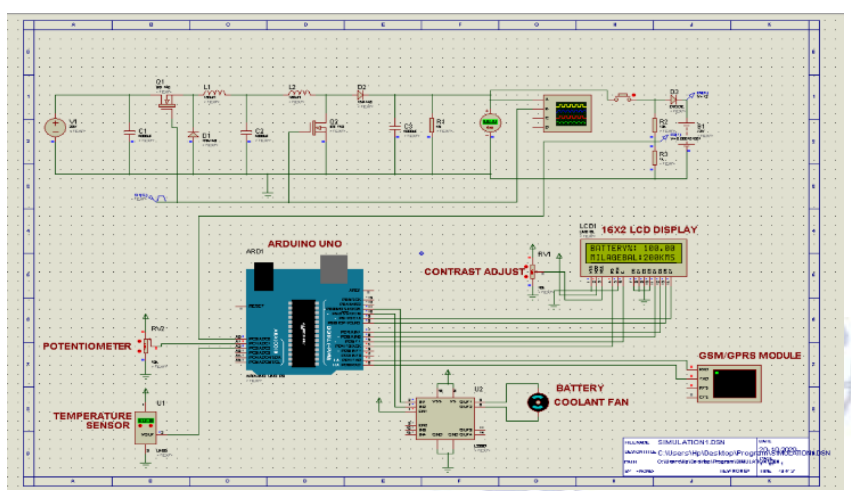

Figure 6 Initial level of Battery status

To analyse the level of the battery status, SMS alerting for the user regarding battery level when the battery of the electric vehicle reaches $50 \%$ is displayed in LCD display given below in figure 7 and virtual terminal display shows the message as given in figure 8 . Battery level when the battery of the electric vehicle reaches $25 \%$ is displayed in LCD display given below in figure 9 and virtual terminal display shows the message as given in figure 10 . The milage of theelectric bike based on battery percentage is given in the figure 11. Call alert for the user when the battery of the vehicle reaches below $10 \%$ is given in figure 12 and figure 13 .

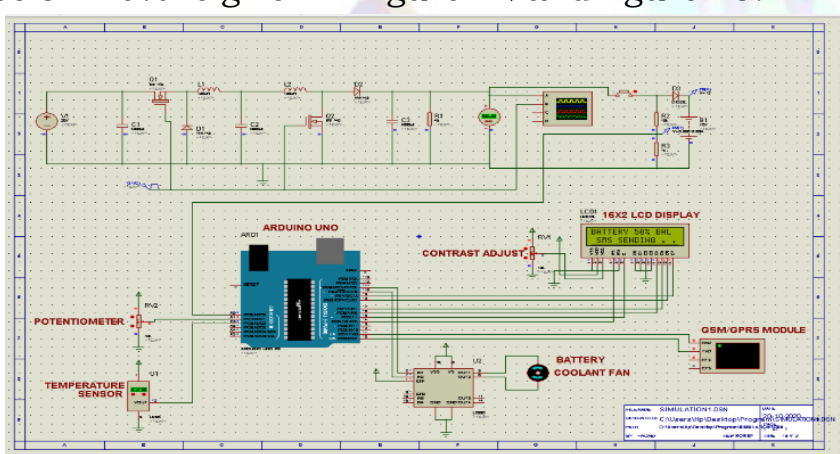

Figure 7 LCD display during $50 \%$ of battery charge

Virtual Terminal

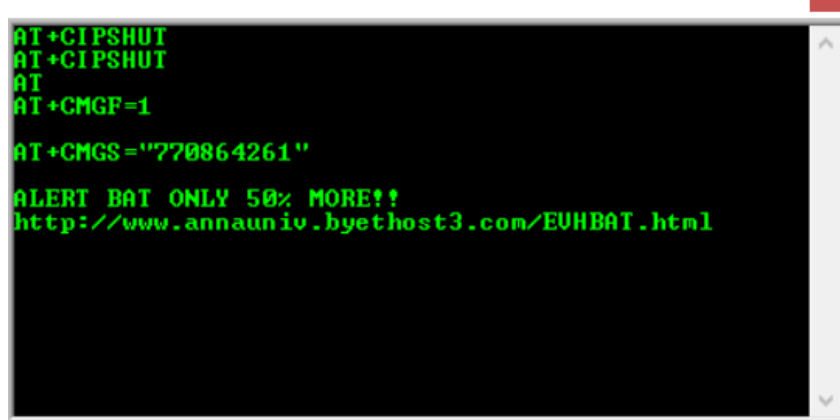

Figure 8 Virtual terminal display of SMS alert for $50 \%$ of battery charge

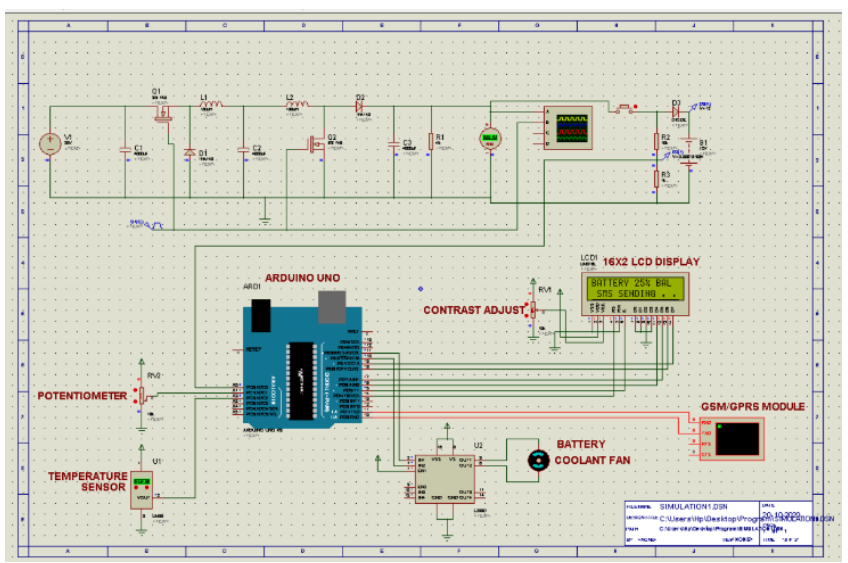

Figure 9 LCD display during 25\% of battery charge Virtual Terminal

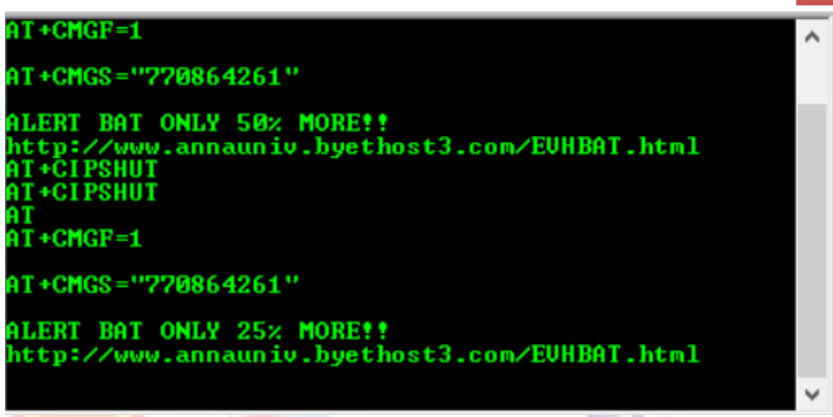

Figure 10 Virtual terminal display of SMS alert for $25 \%$ battery charge

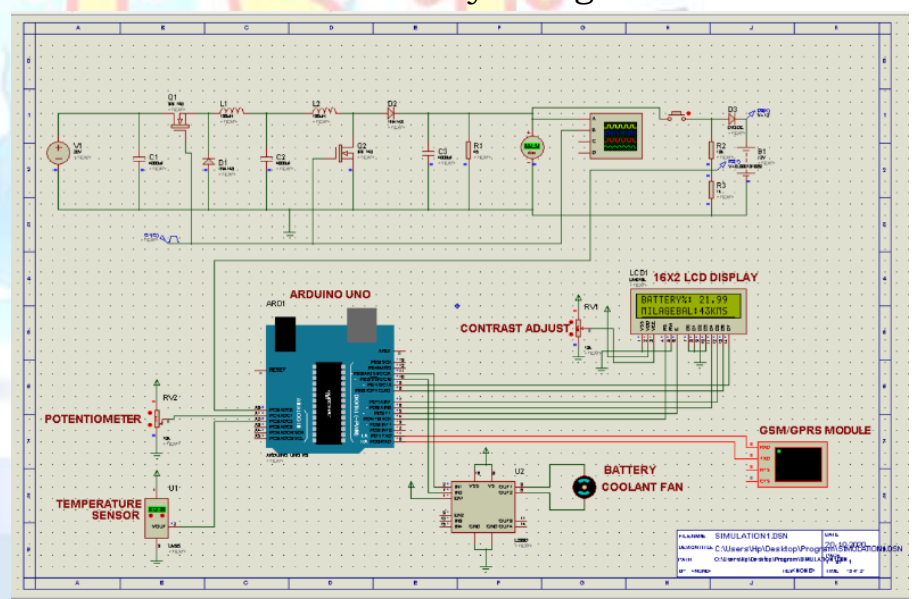

Figure 11 Milage based on battery level of charging

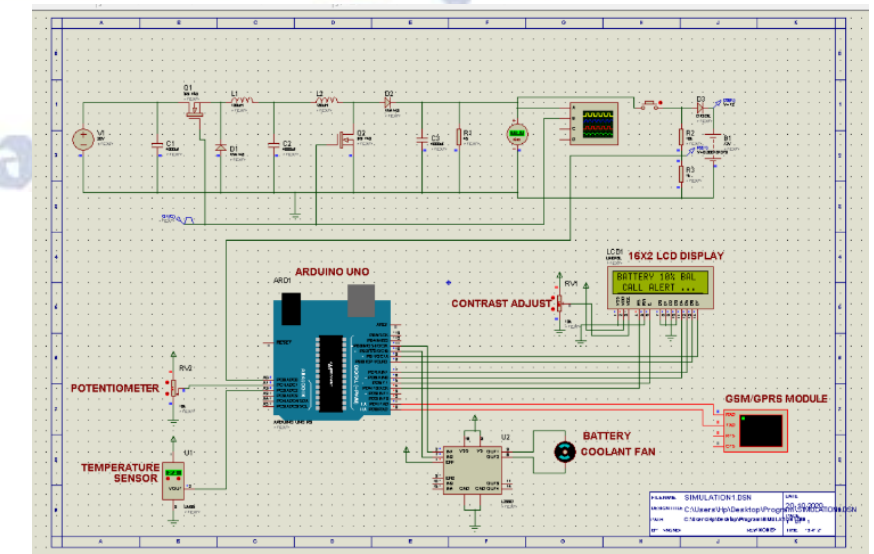

Figure 12 LCD display during $10 \%$ of battery charge 


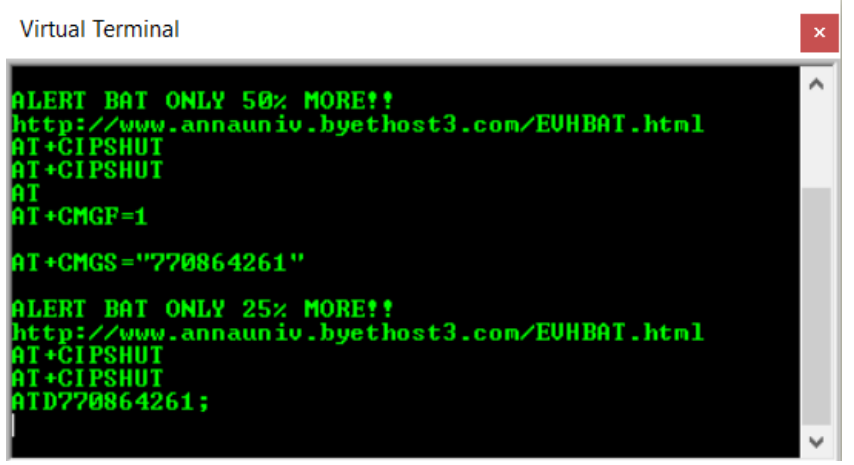

Figure 13 Virtual terminal display of SMS and call alert for below $10 \%$ of battery charge

\section{CONCLUSION AND FUTURE SCOPE}

Less ripple voltage from the cuk converter to be given to the battery is identified.For SOC determination of battery, voltage method is used to identify the battery status by proteus simulation software and SOC determination of battery charging is simulated to analyze the battery performance and Internet of things can be used to estimate the life time of the battery through cloud computing for real time implementation. The battery management for electric vehicles market value will touch USD 8 Billion by 2025. The presence of top notch ABMS developers can impel the expansion of the market across the analysis period.

\section{REFERENCES}

[1] Rouzbeh Reza Ahrabi, Hossein Ardi, Mahdi Elmi, And AliAjami, " A Novel Step-Up Multi Input DC-DC Converter For Hybrid Electric Vehicles Application, IEEE Transactions On Power Electronics, Jan 2016.

[2] G.Shruthi, Mr.SrinivasSingirikonda , "Implementation Of Cuk Converter-Fed BLDC Motor Drive For PFC With Fuzzy Logic Controller", IEEE Transactions On Power Systems, Nov 2017.

[3] A.N. Ravishankar, S. Kumaravel And S. Ashok, "Bidirectional Dual Input Single Output DC-DC Converter For Electric Vehicle Charger Application", IEEE Transactions On Power Electronics, 2019.

[4] Gergana Vacheva, Nikolay Hinov And Vladimir Dimitrov ,"Modelling And Control Of Bidirectional Buck-Boost Converter For Electric Vehicles Applications", IEEE Transactions On Power Converters", 2019.

[5] Yakub Anwar Makandar and Prof. 4 SVanamane,"Performance Analysis of Bidirectional DC-DC Converter for Electric Vehicle Application IJIRST -International Journal for Innovative Research in Science \& Technology| Volume 1 | Issue 9 | February 2015

[6] Premananda Pany, R.K. Singh, R.K. Tripathi, "Bidirectional DC-DC converter fed drive for electric vehicle system", International Journal of Engineering, Science and Technology Vol. 3, No. 3, 2011, pp. 101-110.

[7] C.C. Chan, Alain Bouscayrol, and Keyu Chen, "Electric, fuel-cell and hybrid vehicles: Architectures and modeling, " IEEE Transactions on Vehicular Technology, vol. 59, no. 2, pp. 589-598, February 2010.

[8] A. Lachichi and N. Schofield, "Comparison of DC-DC converter interfaces for fuel cells in electric vehicle applications," Vehicle Power and Propulsion Conference, pp. 1-6, September 6-8, 2016

[9] Xiao Li, WenpingZhang ,Haijin Li, Ren Xie and Dehong Xu "Design and Control of Bi-directional DC/DC converter for $30 \mathrm{~kW}$ fuel cell power system", 8th International Conference on Power Electronics- ECCE Asia,pp: 1024 - 1030, May/June 2011.

[10] Wensong Yu, and Jih-Sheng Lai, "Ultra high efficiency bidirectional DC-DC converter with multi-frequency pulse width modulation, "AppliedPower Electronics Conference and Exposition (APEC), pp.1079-1084, February 2008.
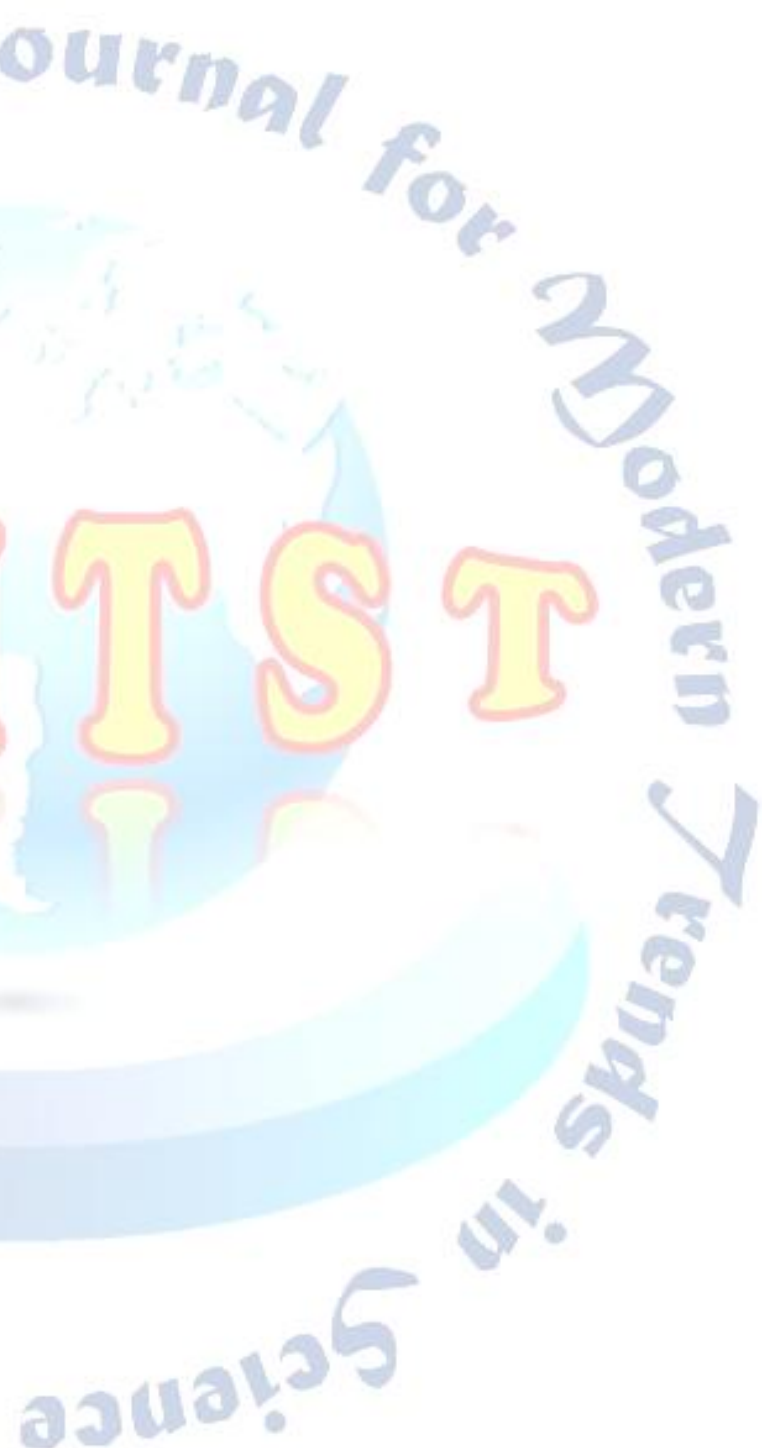

1 International Journal for Modern Trends in Science and Technology 